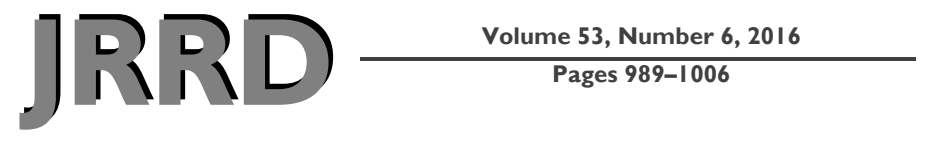

\title{
Tongue-controlled robotic rehabilitation: A feasibility study in people with stroke
}

\begin{abstract}
Sarah Ostadabbas, PhD; ${ }^{1}$ Stephen N. Housley, PT; ${ }^{2}$ Nordine Sebkhi, MS $;^{3}$ Kimberly Richards, PT; ${ }^{2}$ David Wu,

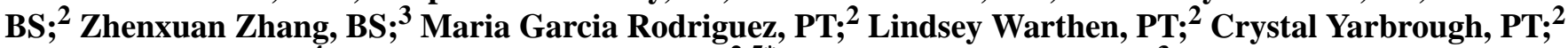
Samir Belagaje, MD; ${ }^{4}$ Andrew J. Butler, PhD, PT; ${ }^{2,5^{*}}$ Maysam Ghovanloo, PhD $^{3}$

${ }^{1}$ Electrical and Computer Engineering Department, Northeastern University, Boston, MA; ${ }^{2}$ Department of Physical

Therapy, Byrdine F. Lewis School of Nursing \& Health Professions, Georgia State University, Atlanta, GA; ${ }^{3}$ School of Electrical and Computer Engineering, Georgia Institute of Technology, Atlanta, GA; ${ }^{4}$ School of Medicine, Emory University, Atlanta, GA; ${ }^{5}$ Atlanta Rehabilitation Research and Development Center, Department of Veterans Affairs, Decatur, GA; and Joint Center for Advanced Brain Imaging, Center for Behavioral Neuroscience, Neuroscience Institute, Georgia State University, Atlanta, GA
\end{abstract}

\begin{abstract}
Stroke survivors with severe upper limb (UL) impairment face years of therapy to recover function. Robotassisted therapy (RT) is increasingly used in the field for goaloriented rehabilitation as a means to improve UL function. To be used effectively for wrist and hand therapy, the current RT systems require the patient to have a minimal active range of movement in the UL, and those that do not have active voluntary movement cannot use these systems. We have overcome this limitation by harnessing tongue motion to allow patients to control a robot using synchronous tongue and hand movement. This novel RT device combines a commercially available UL exoskeleton, the Hand Mentor, and our custom-designed Tongue Drive System as its controller. We conducted a proof-of-concept study on six nondisabled participants to evaluate the system usability and a case series on three participants with movement limitations from poststroke hemiparesis. Data from two stroke survivors indicate that for patients with chronic, moderate UL impairment following stroke, a 15-session training regimen resulted in modest decreases in impairment, with functional improvement and improved quality of life. The improvement met the standard of minimal clinically important difference for activities of daily living, mobility, and strength assessments.
\end{abstract}

Key words: assistive technology, exoskeleton, Hand Mentor, motor cortex, neuroplasticity, robot-assisted therapy, robotic rehabilitation, stroke, Tongue Drive System, upper-limb functional recovery.

\section{INTRODUCTION}

Of the 795,000 individuals who experience a stroke in the United States annually, 80 percent experience upper limb (UL) motor impairment and 90 percent require long-term rehabilitation to regain movement in the impaired limbs [1]. Robot-assisted therapy (RT) shows great promise for improving voluntary UL movement in people with stroke, and it has gained increasing

Abbreviations: AROM = active range of motion, AT = assistive technology, FMA = Fugl-Meyer Motor Assessment, GUI = graphical user interface, HEP = home exercise program, $\mathrm{HM}=$ Hand Mentor, MCID = minimal clinically important difference, $\mathrm{NIH}=$ National Institutes of Health, PROM = passive range of motion, QOL = quality of life, RMSE = root mean square error, ROM = range of motion, RT = robot-assisted therapy, SIS = Stroke Impact Scale, TCS = Tongue Control System, TDS = Tongue Drive System, UL = upper limb, WMFT = Wolf Motor Function Test.

*Address all correspondence to Andrew J. Butler, PhD, PT; Byrdine F. Lewis School of Nursing \& Health Professions, Georgia State University, Urban Life Building, Suite 819; 404-413-1415; fax: 404-413-1090.

Email: andrewbutler@gsu.edu

http://dx.doi.org/10.1682/JRRD.2015.06.0122 
popularity in the past $15 \mathrm{yr}$ [2-8]. RT incorporates key elements of motor learning into a treatment paradigm that includes highly intensive, task-specific, reproducible, and interactive practice. Using $\mathrm{RT}$, the repetitive tasks required during therapy can be delegated to robots while the patient engages in interactive game-like user interfaces and the physical therapist focuses on monitoring progress and selecting appropriate tasks based on outcome measures generated by the RT system.

To date, the majority of commercial RT devices for UL rehabilitation require people with stroke to be able to actively initiate hand motion in order for the device to help complete the movement task [3]. Consequently, treatment options are limited for individuals with severe hemiparesis, who do not possess minimum range of movement after a stroke [9]. Since tongue motion is often preserved in people with stroke because of bihemispheric innervation of the glossopharyngeal nucleus, one way to potentially overcome the current limitation of RT devices (i.e., the need for minimum active wrist movement) is to harness voluntary tongue motion to control the rehabilitation robot. The proposed system in this article targets the unmet need of those who cannot benefit from currently available RTs by extending robotic rehabilitation therapies to those who have severe UL impairment following stroke.

The tongue representation in the motor cortex provides sophisticated motor control with many degrees of freedom, evident in speech and ingestion [10]. Furthermore, the tongue can move rapidly and accurately in almost every direction within the oral space, and it has the added benefit of fatigue-resistant muscle fibers [11], allowing for extended periods of use. Although speech and language are often affected by stroke [12], survivors generally maintain their voluntary tongue control [13], which makes the tongue a potential vehicle for controlling rehabilitation devices.

Further, there is extensive overlap in the cortical representation of the hand and tongue [14]. The two regions have been shown to be highly interconnected functionally, taking part in synchronous activation during independent hand and tongue movements [15-18]. Further regional interconnectivity has been observed in individuals suffering from phantom limb pain, who show extensive cortical activity in deafferented hand representations when purposeful lip and mouth movements are made [19]. The data also suggest that extensive functional reorganization occurs from the lip and mouth region to the deafferented hand cortex. Moreover, it has been demonstrated that topographical alterations of the sensorimotor cortex can shift the motor representation of the tongue into the cortical region of the hand representation [20].

In this work, our aim was to increase the accessibility of RT to the larger stroke population by using tonguedriven RT that does not require the user to have active voluntary hand movement. The rationale for this approach is the idea that synchronizing activities of the hand and tongue may result in reorganization in the primary motor cortex and Broca's area. Prior studies have shown that nonverbal tongue task training can drive neuroplastic changes in human and nonhuman models, with alterations in tongue motor-evoked potentials observed up to $24 \mathrm{~h}$ after the intervention [21-22]. Bourdreau et al. hypothesized that these short-term changes may initiate and propagate the long-term neuroplastic changes required for structural reorganization of neural circuitry [21]. This evidence further supports the use of a tonguecontrolled RT since its motor learning may act as a driver for functional reorganization in the brain following a stroke [23].

Our tongue-driven RT system is the combination of a commercially available and Food and Drug Administration-approved rehabilitation exoskeleton, Hand Mentor (HM) (Motus Nova Inc; Atlanta, Georgia), and our custom-design assistive technology (AT), called the Tongue Drive System (TDS). The HM (Figure 1) is a robotic device used to improve voluntary wrist and finger extension of people with stroke [22]. An air muscle, which is a pneumatic actuator, provides the force necessary to extend the wrist and resist wrist flexion in order to improve active range of motion (AROM). The primary advantage of the HM is its consistent delivery of highintensity, repetitive, and longitudinally reproducible therapeutic training. However, similar to other modes of rehabilitation, the HM requires minimal voluntary UL movement.

The robot controller component, TDS (Figure 2), is a wireless and wearable technology that provides unobtrusive access to the physical volitional motion of the tongue [24-27]. It consists of a small magnetic tracer (Figure 2(a)) that is temporarily attached to the tongue via adhesive and a wireless headset that positions an array of magnetic sensors on both sides of the face near the cheeks (Figure 2(b)). TDS can track tongue motion by analyzing changes in the magnetic field and then converting them to a set of user-defined control commands. 
(a)

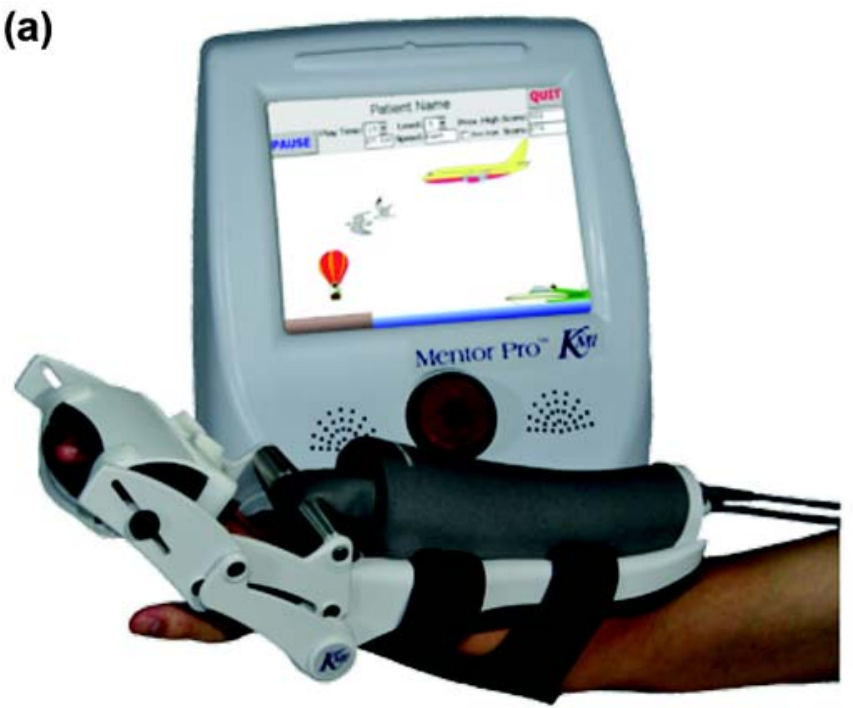

(b)

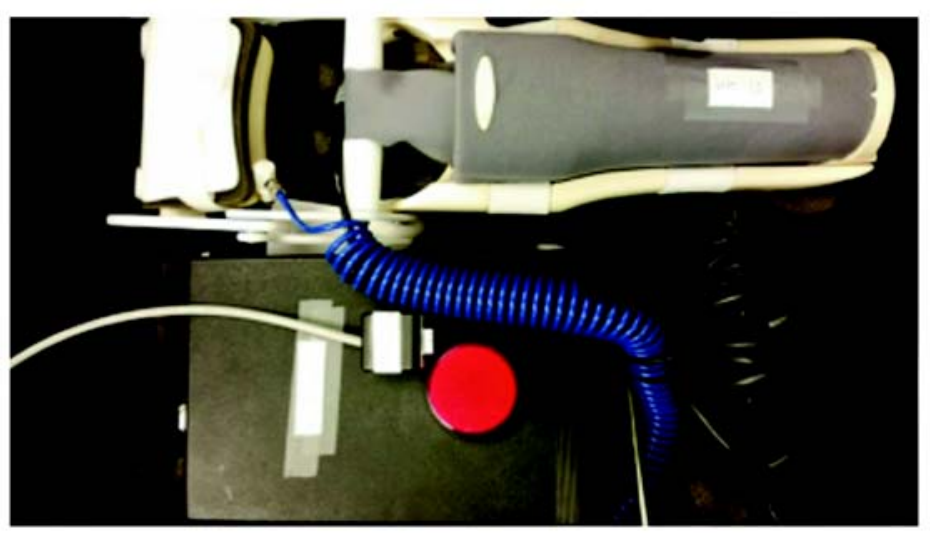

Figure 1.

(a) Illustration of the Hand Mentor unit and (b) actual unit used during study.
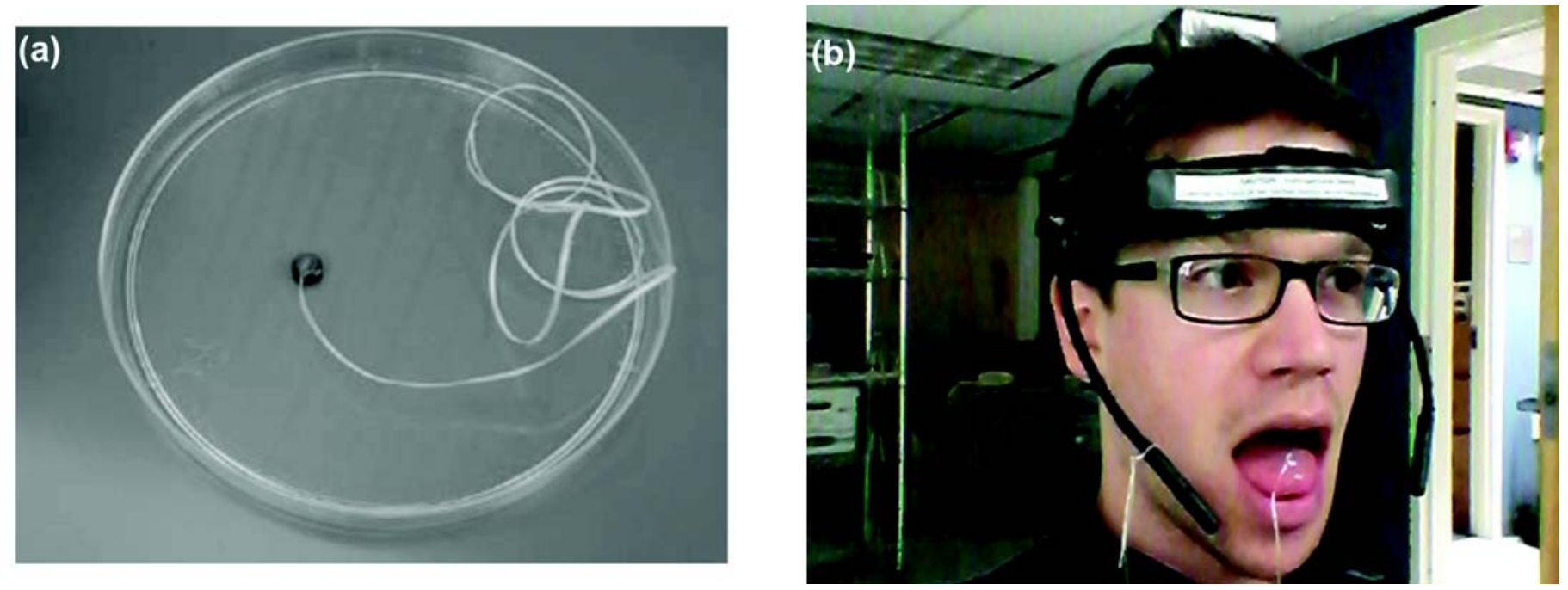

Figure 2.

(a) A thin string of dental floss attached to a magnetic tracer using super glue and covered with medical grade epoxy. The magnetic tracer is covered with silicone rubber to have a soft upper surface. (b) Participant wearing a Tongue Drive System (TDS) headset that positions an array of magnetic sensors on both sides of the face near the cheeks. The magnetic tracer is attached to the participant's tongue, about $1 \mathrm{~cm}$ back from the tip. The other end of the floss is tied to one of the two poles of the TDS headset to eliminate any risk of swallowing or aspirating the magnetic tracer even if it is detached from the participant's tongue during the experiment.

In the combined TDS-HM system, the TDS is connected to the HM device through a USB interface so that movement of the tongue results in movement of the hand unit. The user attempts to move the paretic hand while using the tongue to drive motion; however, active motion of the wrist and hand is not necessary to drive the unit. The technical details of the TDS-HM design have been previously published [28]. 
The current feasibility study was designed to determine whether the TDS-controlled HM system is a realistic rehabilitation solution for patients with nonexistent or very limited AROM. The TDS-HM system was tested through a proof-of-concept study on six nondisabled participants and three people with stroke with mild-to-moderate impairment. We hypothesized that increases in range of motion (ROM) of the wrist affected by stroke would be detected following $30 \mathrm{~h}$ of tongue-assisted HM training. To the best of our knowledge, the closest research to the study we report here is from the Center for Sensory-Motor Interaction (Aalborg University, Denmark), which has developed a tongue-controlled AT, called the Tongue Control System (TCS) [29-30]. However, that research has focused on the TCS as an AT, while our research focuses on the applicability of the TDS as part of RT.

\section{METHODS}

The most successful RT interventions have been shown to include movements that are task-specific and goal-directed rather than general and nonspecific [3132]. Additionally, goal-directed tasks have been found to be engaging and challenging [33] and to allow for multiple attempts or repetitions [34]. These principles guided the development and design of the TDS-HM intervention. We developed a software/algorithm and a graphical user interface (GUI) to enable people with stroke to control the HM by harnessing tongue movements. The GUI provides audiovisual feedback and a game-like, goal-oriented environment to engage participants in the rehabilitation paradigm. In this study of the TDS-HM intervention, participants were asked to perform the repetitive task of tracking a moving waveform spanning inside and outside the wrist AROM. Performance was measured using root mean square error (RMSE) between the target and actual wrist angles.

\section{Study Participants}

After institutional review board approval and written informed consent were received, six nondisabled individuals (two male) with no history of neurological disorder and three individuals diagnosed with ischemic stroke (two male) were enrolled in a multiple-week robotic rehabilitation trial. The average time since stroke for participants with stroke was 2 yr and 11 mo. Participants' demographic information is presented in Table $\mathbf{1}$.

\section{Experimental Design}

Early stage tests of the TDS-HM system were carried out on six nondisabled participants during three $2 \mathrm{~h}$ long sessions over a week to determine proper functioning of the interface between the HM exoskeleton and the TDS tongue-control module. The feasibility of performing waveform tracking and motor learning was also tested. Tracking accuracy was evaluated with RMSE; when this shows consistent improvement over time, it can be considered a sign of motor learning by the user. Preliminary tests using different control modes of operation with the nondisabled participants demonstrated that the discrete mode resulted in the lowest RMSE in tracking tasks [35].

Following early stages of testing, a case series involving three participants with stroke was performed. For two of these participants, with mild-to-moderate levels of impairment, the TDS-HM intervention was conducted in three $2 \mathrm{~h}$ sessions per week for $5 \mathrm{wk}$, for a total of 15 sessions. For one of these participants, with AROM in normal limits, only six $2 \mathrm{~h}$ sessions were conducted.

During each $2 \mathrm{~h}$ session, participants first underwent a setup phase (attaching the TDS, attaching the HM, and

Table 1.

Study participant demographic information.

\begin{tabular}{|c|c|c|c|c|c|c|c|c|c|}
\hline \multirow{2}{*}{ Participant } & \multirow{2}{*}{ Sex } & \multirow{2}{*}{$\begin{array}{l}\text { Age } \\
\text { (yr) }\end{array}$} & \multirow{2}{*}{$\begin{array}{c}\text { Paretic } \\
\text { Hand }\end{array}$} & \multirow{2}{*}{$\begin{array}{l}\text { Date of } \\
\text { Injury }\end{array}$} & \multirow{2}{*}{$\begin{array}{c}\text { Time Since } \\
\text { Stroke }\end{array}$} & \multicolumn{2}{|c|}{ Wolf Motor Function Test (s) } & \multicolumn{2}{|c|}{ Fugl-Meyer } \\
\hline & & & & & & Pre & Post & Pre & Post \\
\hline \multicolumn{10}{|l|}{ With Stroke } \\
\hline 1 & Female & 61 & Right & $10 / 26 / 12$ & $35 \mathrm{mo}$ & $2.44 \pm 2.04$ & $2.65 \pm 2.12$ & 66 & 66 \\
\hline 2 & Male & 50 & Right & 3/13/13 & $30 \mathrm{mo}$ & $9.34 \pm 12.57$ & $6.66 \pm 7.52$ & 32 & 42 \\
\hline 3 & Male & 79 & Left & $5 / 16 / 12$ & $40 \mathrm{mo}$ & $4.68 \pm 5.10$ & $4.60 \pm 5.49$ & 42 & 53 \\
\hline Nondisabled & $\begin{array}{c}4 \text { Females, } \\
2 \text { Males }\end{array}$ & $23-49$ & NA & NA & NA & NA & NA & NA & NA \\
\hline
\end{tabular}


positioning all devices with comfort and functionality as the primary aim). Participants then completed calibration and calibration training with the TDS to accurately set the TDS control system. Following this, training with the waveforms and modes took place. Participants completed three different waveforms for the discrete mode for up to 10 min increments each waveform. Participants were encouraged to indicate their need for a 1 to 2 min break between waveforms when they required one. The intervention was based on an intervention protocol used for constraint induced therapy [36] and for robotic therapy [37].

AROM was measured at the beginning of each session for participants with stroke to monitor its evolution. We anticipated that these participants would achieve a positive minimal clinically important difference (MCID) in function as measured by the Stroke Impact Scale (SIS), Wolf Motor Function Test (WMFT), and Fugl-Meyer Motor Assessment (FMA) (as explained in the "Motor Assessment" section) when comparing pre- and postrehabilitation using the RT system.

\section{Tongue Drive System-Hand Mentor}

Figure 3 shows the functional block diagram of the TDS-HM system. A small magnet, the size of a lentil, was glued temporarily to the tip of the participant's tongue. Changes in the magnetic field caused by tongue movement were measured by the TDS magnetic sensors and wirelessly delivered to a computer to be translated into a pair of discrete commands (up and down) using our sensor-signal processing algorithms [24]. At the same time, the actual wrist angle was measured by a potentiometer embedded in the HM and reported to the computer.

Using TDS, volunteers controlled the HM by placing their tongues in predefined positions within the oral cavity. While receiving real-time visual feedback, participants were instructed to track one of three types of waveforms shown in Figure 4-(a) sinusoidal, (b) rectangular, and (c) triangular shape-for 5 min as accurately as possible with their involved hand (and the simulated paretic hand in nondisabled participants). Three distinct waveforms simulated different types of tasks that users may perform with their hand in daily activities, ranging from sudden changes (i.e., randomized rectangular waveform) to smooth changes (represented by a sinusoidal waveform) and a combination of smooth and sudden (as in the triangular waveform). Three types of tracking waveforms were used in order to avoid the boredom of

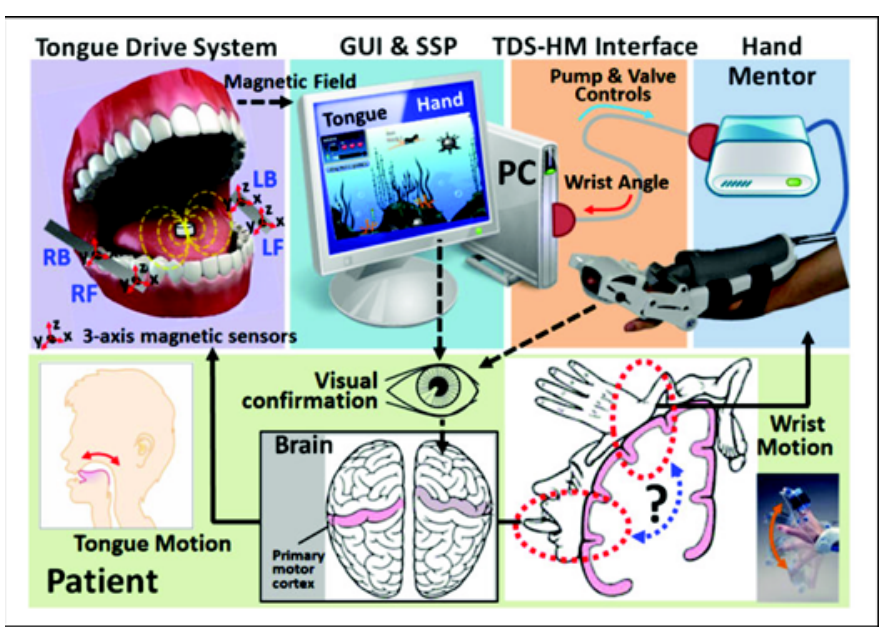

Figure 3.

Functional block diagram of the wearable Tongue Drive System (TDS) paired with the robotic Hand Mentor (HM). TDS and HM, shown on the upper left and right, respectively, are both connected to a personal computer (PC). TDS magnetic sensors (left front [LF], left back [LB], right front [RF], and right back [RB]) data are translated into up and down commands using our sensor-signal processing (SSP) algorithms. Synchronously, the actual wrist angle is measured by the $\mathrm{HM}$ and reported to the PC. The software represents both the tongue position and wrist angle on the graphical user interface (GUI) screen, which is embedded in an interactive game-like biofeedback environment for the user. Reprinted by permission of American Society of Mechanical Engineers (ASME) Publications, New York, NY, September 1, 2015.

tracking one particular waveform for a $2 \mathrm{~h}$ training session. The three waveforms were presented in a pseudorandom order.

Depending on the wrist position, participants could generate commands by either actively moving their hand when inside their AROM or using the TDS to control the HM to move their hand passively when outside their AROM. The range outside AROM was referred to as the passive ROM (PROM).

During the experiment with nondisabled participants, tracking was done using three different control modes: discrete, semiproportional, and proportional command [28]. Our previous work [35] led us to conclude that the discrete mode is the most robust control paradigm given the current status of the TDS-HM hardware and signal 
(a)

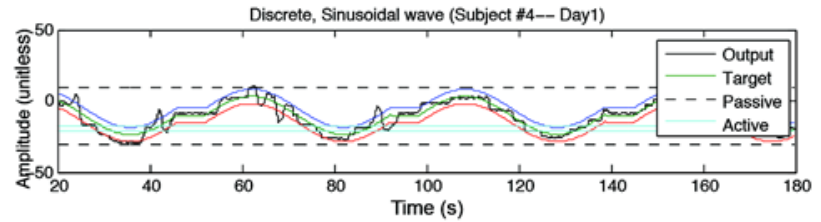

(b)

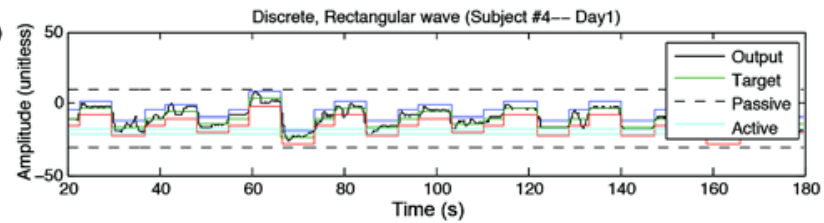

(c)

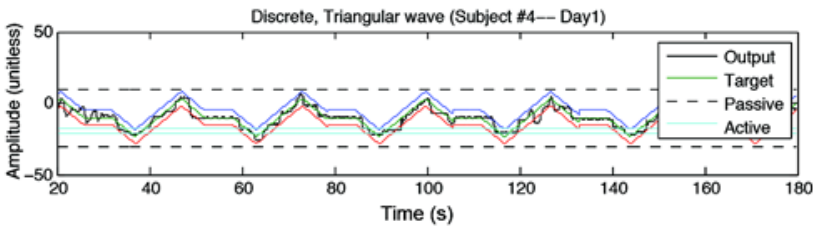

Figure 4.

Output and target signals for three waveforms from one nondisabled participant's experiment during session 1 using discrete command control mode.

processing algorithm, and therefore this was used with the participants with stroke.

Figure 4 shows tracking output (black solid line) and target (green solid line) signals for three waveforms from one nondisabled participant's trial using the discrete command control mode during session 1. The AROM and PROM limits are shown in this figure by blue solid and black dashed horizontal lines, respectively. Waveform tracking accuracy within the PROM was assessed as a measure of performance using TDS-HM technology in both nondisabled participants and participants with stroke.

\section{Motor Assessment}

The following assessments were conducted at various points during the TDS-HM intervention for all participants with stroke. ROM was recorded daily, while the WMFT, FMA, and the SIS were logged preintervention and postintervention to evaluate the preliminary efficacy of the rehabilitation paradigm and ensure adequate daily calibration of the HM device. The nondisabled participants were assessed only on daily RMSE performance.

1. ROM-Active and passive wrist extension ROM was measured goniometrically, as standardized by Norkin and White [38]. Measurements were taken preintervention to establish a baseline and postintervention to assess change. To (1) capture the changes occurring throughout the total available ROM, (2) take into account interrater measurement error seen with goniometric devices, and (3) normalize daily variability in PROM measures, ROM measures were also taken before each training session and converted to a ratio. This ratio was calculated by dividing the AROM for a given session by the average PROM over the course of the 15-session intervention. Scores could range from 0 to 1 , with higher scores indicating more active control over PROM.

2. WMFT-WMFT is a quantitative time-based method for evaluating UL performance while providing insight into joint-specific and total limb movements [39]. This 17-item test consists of 15 functional assessments that measure time-based performance in normal functional tasks and 2 force-based tasks that assess lifting weight and grip strength. The functional items range in difficulty, first requiring single and proximal joint motions, and then progressing to combined joint motions involving the distal limb segments used to achieve normal functional tasks such as reaching for, grasping, and lifting a glass. Because of the skewed distribution of WMFT performance times (scores ranged from 0 to $121 \mathrm{~s}$ ), logarithmic transformation was performed to normalize the data. WMFT logs were converted back to seconds to assist in the interpretation of the results.

3. UL portion of the FMA-FMA evaluates motor function, balance, sensation, and joint function and measures recovery in poststroke hemiplegic patients [40]. The UL portion of the FMA consists of 33 items that evaluate movement, segmental coordination, and reflexes for each joint of the UL. Scores range from 0 to 66 (normal function).

4. Hand function subscale of the SIS-SIS 3.0 is a multidimensional instrument to measure quality of life (QOL) in people with stroke [41]. The SIS contains 59 questions in 8 domains, the first 4 of which measure a participant's perception of physical ability. The hand subscale asks questions about how stroke has impacted the use of the affected hand. SIS scores range from 1 to 5. For assessment, the SIS mean score was utilized.

\section{Data Analysis}

\section{Root Mean Square Error}

To calculate waveform tracking error, each target waveform was divided into blocks with approximately 
the same length, and the RMSE of block $j, R M S E_{j}$, for each trial was calculated using-

$$
E_{i}=\text { Output }(i)-\operatorname{Target}(i) \text {, for } 1 \leq i \leq N_{j}
$$

and

$$
R M S E_{j}=\sqrt{\frac{\sum_{i=1}^{N_{j}} E_{i}^{2}}{N_{j}}}, \text { for } 1 \leq j \leq K,
$$

where Output(i) and Target(i) are the ith values of the participant's tracking output and the tracking target, respectively. $N_{j}$ is the number of data points in block $j$, and $K$ is the number of blocks in a given trial. The overall RMSE in a given trial, $R M S E_{\text {overall }}$, can be calculated using $R M S E_{j}$, if the length of each block, $N_{j}$, is equal to $N$ :

$$
R M S E_{\text {Overall }}=\sqrt{\frac{\sum_{i=1}^{N \times K_{E_{i}^{2}}}}{N \times K}}=\sqrt{\frac{\sum_{j=1}^{K} R M S E_{j}^{2}}{K}} .
$$

\section{Statistical Analysis}

Descriptive statistics, means, and standard deviations were computed for RMSE data from all nine participants and for clinical measures from the three participants with stroke. Paired $t$-tests were performed to evaluate the changes in RMSE from pre-to-post training for the nondisabled participants. Repeated measures analyses of variance were performed across all training sessions for the participants with stroke. Post hoc least significant differences adjustments were performed to explore all possible pairwise comparisons of means. The level of significance was set at $p<0.05$, and all tests were twotailed. All data met the assumptions of the tests used to analyze them. SPSS version 22.0 (IBM Corporation; Armonk, New York) was used for the statistical analyses.

\section{RESULTS}

\section{Nondisabled Participants}

Six nondisabled individuals simulated UL impairment, allowing us to test the functionality of the TDSHM system in terms of ease of use and robustness of the different modes of operation [28]. Specifically, we looked at whether training with TDS-HM would result in RMSE reduction over the course of three sessions in nondisabled participants.

Nondisabled participant 1's data were eliminated from the analyses because of the presence of audio distraction in the laboratory during the experiment, which reduced the person's ability to concentrate. We made sure that the environment was quiet for the remainder of the trials. AROM measurements were not analyzed since all of the nondisabled participants had a fully functional UL and increases in daily AROM were only simulated. For these participants, at the beginning of each session a target AROM was manually set in the software so that the system would switch between modes (active or passive) based on the AROM limits.

Among the five nondisabled participants, the RMSE in PROM averaged over all command modes and waveforms started at $5.28 \pm 2.06$ in session 1, dropped to $4.17 \pm 1.14$ in session 2 , and finally dropped to $2.83 \pm$ 1.17 in session 3 .

There was a statistically significant decrease in RMSE from session 1 to session 3 (Figure 5(a), $p<$ 0.001). The decrease in tracking error among all nondisabled participants demonstrated improvement in performance and motor learning after $3 \mathrm{~d}$ of training. When analyzed individually based on the mode of operation, however, only the discrete and proportional modes were significantly different (Figure 5(b), $p<0.001$ and $p=$ 0.004 , respectively) in terms of RMSE.

The proof-of-concept trials on nondisabled participants thus indicated that TDS-HM in PROM (when TDS initiates the HM robot movement) is highly robust in the discrete mode of control. Interestingly, when average RMSE was compared between modes, the discrete mode also showed the lowest final RMSE for each individual. Therefore, we used the discrete mode as the only mode of control in our case series experiments with people with stroke.

\section{Case Series with Participants with Stroke}

\section{Stroke Participant 1}

Our first participant was a $61 \mathrm{yr}$ old high-functioning female with no UL ROM deficits. Participant 1 was included to evaluate the safety and the rate of learning in used TDS-HM for a novice poststroke participant. The experiment was conducted in six sessions, and no adverse 
(a)

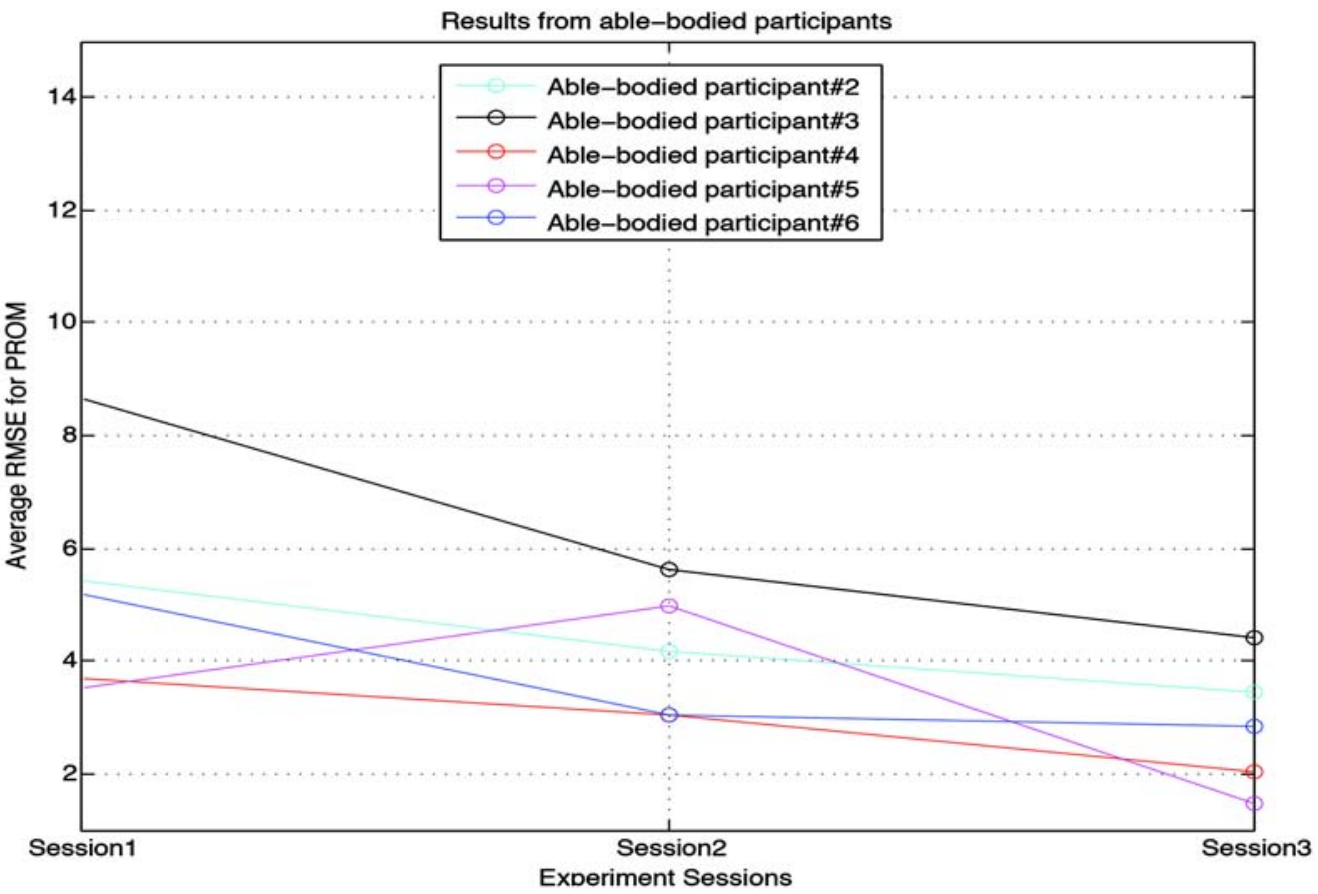

(b)
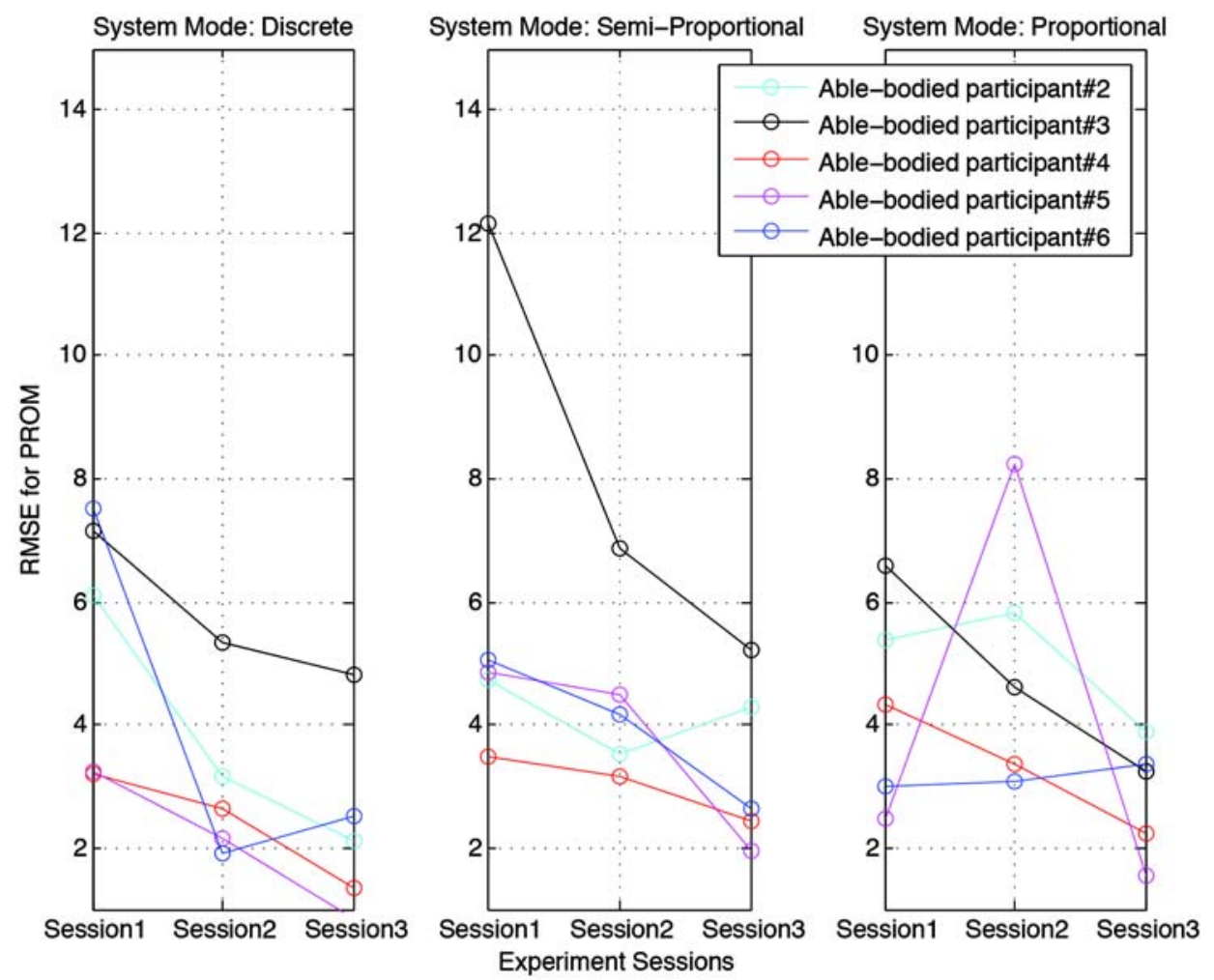

Figure 5.

(a) Average root mean square error (RMSE) for passive range of motion (PROM) by session from each nondisabled participant. (b) RMSE for PROM by session and control mode from each nondisabled participant. 
events were reported. Analysis of the results showed that after five sessions of training, the participant achieved a minimum average RMSE of $4.37 \pm 2.05$. As expected based on pre- and posttraining WMFT performance, there was no change in UL function following use of the TDS-HM over the 2 wk period of intervention. Feedback from the participant throughout the experiment helped us to adjust the speed of the tracking trials and their length for our next two participants.

\section{Stroke Participant 2}

Our second participant was a 50 yr old male with moderate UL impairment (based on the preintervention FMA score) and limited wrist movement. Figure 6 shows RMSE in the discrete mode for PROM by session and waveform types for this participant. The average RMSE for the discrete mode in sinusoidal waveform tracking showed statistically significant decreases, from $16.50 \pm 5.58$ in session 1 to $7.08 \pm 4.29$ in session $6(p<$ $0.001)$ and to $2.94 \pm 0.77$ in session $15(p<0.001)$. This participant was able to perform all 15 WMFT time-based tasks completely during pre- and postevaluations. Preand post mean WMFT performance time decreased for his paretic arm, while performance time for his uninvolved arm remained unchanged. Summed WMFT performance time improved more than the previously validated MCID ( $\geq 19$ s improvement) [42]. WMFT force-based tasks showed varied results, with grip strength improving and the amount of weight lifted remaining unchanged. FMA scores improved (higher numbers indicate less impairment) from pre- to posttreatment more than the previously validated MCID $(\geq 10$ point improvement) [43]. PROM and AROM showed marked increases from baseline, resulting in improved ratio scores. Self-reported QOL also improved, as measured by SIS dimensions of strength, mobility, and activities of daily living, beyond the previously validated MCID levels ( $\geq 9.2, \geq 5.9$, and $\geq 4.5$ point improvement, respectively) [44]. The newly formulated physical cluster increased [45]; however, no validated MCID has been reported in the literature. Table 2 shows the outcome measures for this participant.

\section{Stroke Participant 3}

This participant was a 79 yr old male with poor spatial awareness of his impaired UL. He had frequent small amplitude corrective movements for both his impaired hand and tongue that mimicked tremor. Figure 7 shows the RMSE in the discrete mode for PROM by session and waveform types for this participant. RMSE decreased significantly, from $9.76 \pm 1.92$ in session 1 to $7.75 \pm 1.09$ in session $15(p<0.001)$. Following the TDS-HM intervention, he was able to perform both the pencil lift and paperclip lift tasks, increasing the number of WMFT time-based tasks he could complete to 14 out of 15 , as compared to his pretreatment score of 12 out of 15. Mean

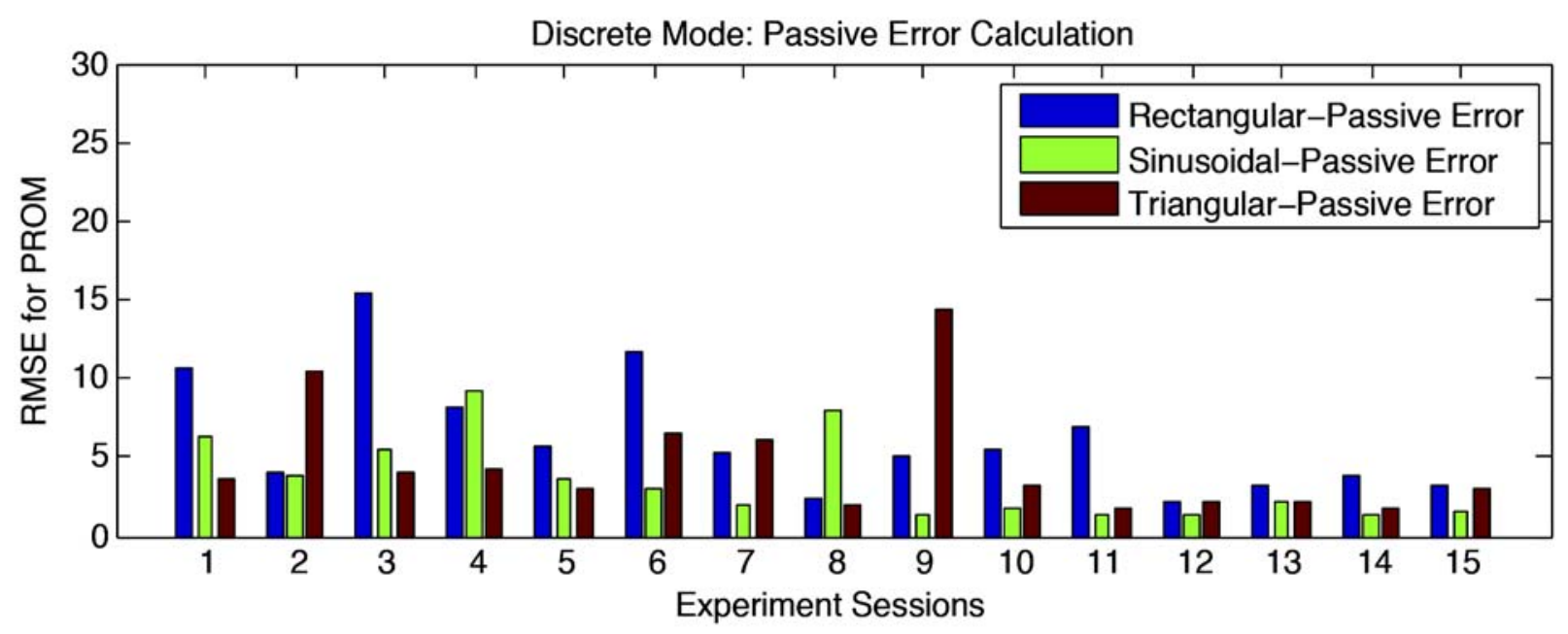

Figure 6.

Root mean square error (RMSE) in discrete mode for passive range of motion (PROM) by session and waveform type for stroke participant 2. 
JRRD, Volume 53, Number 6, 2016

Table 2.

Outcome measures for stroke participant 2.

\begin{tabular}{|c|c|c|c|}
\hline Outcome Variable & Baseline & Posttreatment & Change from Baseline \\
\hline \multicolumn{4}{|l|}{ Paretic Limb } \\
\hline WMFT Performance Time (s) & $140.04 \pm 12.57$ & $99.94 \pm 7.52$ & $40.1(28.63 \%)^{*}$ \\
\hline \multicolumn{4}{|l|}{ Nonparetic Limb } \\
\hline WMFT Performance Time (s) & $21.91 \pm 1.58$ & $20.68 \pm 0.96$ & $1.23(5.61 \%)$ \\
\hline Mean WMFT (s) ${ }^{\dagger}$ & $1.46 \pm 1.58$ & $1.37 \pm 0.96$ & 0.082 \\
\hline Weight Lifted (kg) & 9.09 & 9.09 & 0.00 \\
\hline Grip (kg) & 6.00 & 9.33 & 3.33 \\
\hline No. Tasks Not Completed Within 120 s & 0 & 0 & 0 \\
\hline FMA UL Motor Score & 32 & 42 & $10^{*}$ \\
\hline RMSE: Discrete Mode Sine Wave & $16.50 \pm 5.58$ & $2.94 \pm 0.77$ & $13.56^{\S}$ \\
\hline Ratio of Active/Passive ${ }_{\text {avg }}$ Range of Motion & 0.143 & 0.543 & 0.400 \\
\hline \multicolumn{4}{|l|}{ SIS } \\
\hline Hand Function & 25 & 45 & $20^{*}$ \\
\hline ADL & 77.5 & 90.0 & $12.5^{*}$ \\
\hline Mobility & 80.56 & 88.89 & $8.33^{*}$ \\
\hline Strength & 56.25 & 68.75 & $12.50^{*}$ \\
\hline Physical & 66.07 & 78.57 & 12.50 \\
\hline \multicolumn{4}{|c|}{$\begin{array}{l}{ }^{*} \text { Achieved minimally clinical important difference. } \\
{ }^{\dagger} \text { Data in normalize log transformation utilized for subsequent analysis. } \\
{ }^{\ddagger} \text { Performance time is converted to } \log _{10} \text { for analysis. } \\
{ }^{\S} p<0.001 \text {. } \\
\text { ADL = activity of daily living, FMA = Fugl-Meyer Motor Assessment, RMSE = root mean square error, SIS = Stroke Impact Scale, UL = upper limb, WMFT } \\
\text { Wolf Motor Function Test. }\end{array}$} \\
\hline
\end{tabular}

WMFT performance timed tasks showed no change at posttreatment evaluation. However, the total WMFT performance time improved by a clinically validated level. WMFT performance tasks showed varied results, with grip strength decreasing and weight lifted improving. At posttreatment assessment, FMA UL motor scores showed increases from pretreatment by a level greater than the validated MCID ( $\geq 10$ point improvement) [43]. PROM and AROM had also improved at posttreatment evaluation. ROM ratio scores showed slight improvements. SIS dimensions of hand function, strength, mobility, and activities of daily living improved beyond the previously reported MCID $(\geq 17.8, \geq 9.2, \geq 4.5$, and $\geq 5.9$ point improvement, respectively). The newly formulated physical cluster improved; however, no validated MCID has been reported in the literature. Table 3 shows the outcome measures for participant 3.

\section{DISCUSSION}

We hypothesized that the synchronous use of the tongue and hand in robot-assisted exercises, followed by a gradual reduction in tongue control, would improve function and QOL in people with stroke with UL impairment. We first showed the successful application of the TDS-HM combination, a robust tongue-controlled RT system, in experiments performed by six nondisabled participants in a laboratory environment. Next, we examined application of TDS-HM with participants with stroke. The outcome measures from two participants with stroke indicated that a 15 -session training regimen for these patients with chronic, moderate UL impairment following stroke resulted in modest decreases in impairment, with functional improvement and improved QOL. 


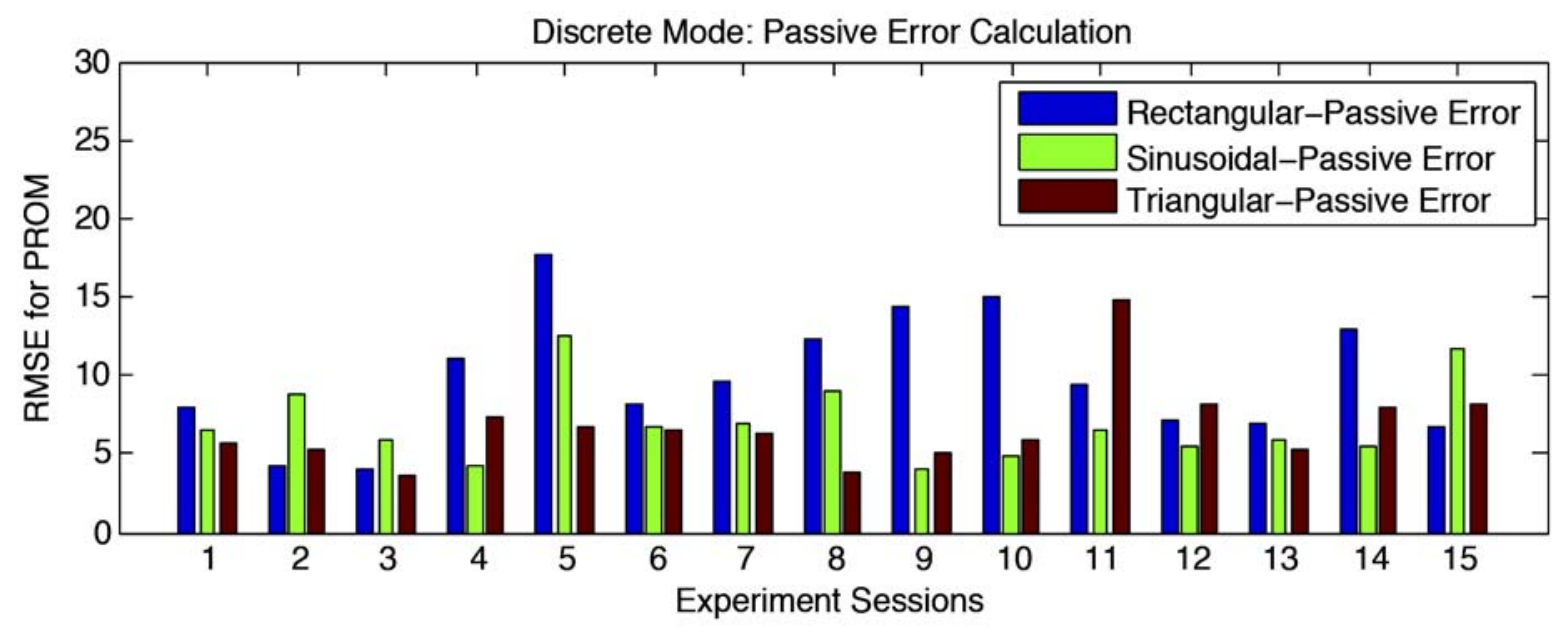

Figure 7.

Root mean square error (RMSE) in discrete mode for passive range of motion (PROM) by session and waveform type for stroke participant 3.

The use of the HM by itself has been shown to improve AROM of distal musculature at 3 to 9 mo poststroke [37]. A telerehabilitation study that evaluated the effectiveness and compliance of a home robotic therapy program for patients with stroke for 2 to 3 mo (VA11810-RP) found that participants using the HM showed improvements in depressive symptoms, functional independence, and use of the UL and small (3.1\%) increases in Total Functional Independence Measure scores. The participants also showed clinically significant improvements in Action Reach Arm Test scores (18.7\%, $p=$ 0.01). A recent large randomized controlled trial compared the effects of the HM in combination with a home exercise program (HEP) with the effects of HEP alone on moderately impaired patients with stroke (as indicated by baseline FMA scores of $34.1 \pm 12.1$ and $33.3 \pm 12.0$, respectively) [46]. They found that the combination of HM and HEP and a dose equivalent HEP therapy alone were equally effective, suggesting that both traditional and HM augmented therapies are effective in improving UL outcomes. Nevertheless, the preliminary studies indicate that the HM robot can be used to increase compliance and facilitate UL motor recovery, and it has the potential to be a cost-effective rehabilitation device for moderately impaired patients with stroke. To date, however, the efficacy of the HM in improving UL function in severely impaired people with stroke has not been tested because of their inability to voluntarily activate wrist movement. Although the current study enrolled only mild to moderately impaired people with stroke, as indicated by baseline FMA scores of 32 and 42, in this feasibility study we combined two technologies to capitalize on residual motor activity in the tongue to improve the efficacy of the overall HM intervention. With significant cortical overlap between tongue and hand [14] and the known tendency for cortical reorganization between these two regions of the brain [20], it seems reasonable to expect that using tongue-assisted HM control can provide the level of assistance needed by severely limited people with stroke to actively participate in this rehabilitation program. Further, no studies to date have utilized effective methods of objectively tracking motor performance improvements on a daily basis. With the inclusion of RMSE motor performance tracking data, we believe that we have found a reliable method of objectively assessing improvements in motor performance on a trial-by-trial basis.

In our study, the decrease in tracking error, as measured by RMSE, suggests that there were improvements in motor performance after training with the TDS-HM in both nondisabled participants and participants with stroke. Accurately tracking waveforms did not transfer into improved UL function in participant 1 . However, the lack of transfer may have been due to a ceiling effect, considering UL function of participant 1 was initially high $($ FMA $=66)$. Participant 2 showed improvements from pre- to postintervention in functional performance, as assessed by WMFT performance times and FMA scores, 
group, limiting our ability to draw conclusions about the efficacy of the TDS-HM.

One limiting factor in investigating the clinical effect of using TDS-HM on AROM in this study was the fact that the participants with stroke were higher functioning than the intended target population for the TDS-HM technology in terms of UL motor impairment. A significant knowledge gap exists as to whether participation in a TDS-HM intervention can improve UL function in people with stroke with severe UL impairment. Future studies will enroll more severely impaired people with stroke.

Regardless of residual AROM, participants are instructed to perform the training sessions using the same strategy. They are instructed to engage both the tongue and hand to the best of their abilities to successfully execute the rehabilitation activity. Therefore, a person with stroke with no AROM would still be instructed to use synchronous hand and tongue movement. The decrease in RMSE demonstrated that people with stroke learned that task and were able to synchronously use the tongue and hand. Therefore, people are able to learn the task regardless of their level of impairment. The innate motor learning ability may translate to more severely impaired patients with stroke with no AROM.

Furthermore, the theoretical construct that underpins the notion that the TDS-HM will enhance functional recovery in more severely impaired people relies on interventions being designed to modulate neural activity in sensorimotor regions to facilitate acute changes in the brain. With chronic activity modulation, acute changes in brain signaling can begin to be transferred to propagating of new pathways and possibly circumventing existing damage [50-55]. Furthermore, arm muscles are preferentially unilaterally innervated, whereas tongue muscles are bilaterally innervated. This is important for our work because even in severe strokes in which arm function is severely impaired, tongue muscles remain intact (unless it is a brainstem stroke).

Some technical considerations and limitations should also be noted. The discrete mode was the most robust mode of command (no unexpected technical challenges), but it is limited to up, down, and neutral motions made by the tongue. Using a control mode more compatible with human cognitive and motor processes has been shown to be more effective in controlling neuroprosthetic systems [56]. Effective matching of command signals to appropriately configured device functions may enable more intuitive and natural control of the RT systems. Thus, further improvement in usability, particularly in the context of game-based tasks, may be achieved by changing the HM control mechanism from a discrete to a proportional mode. Proportional control will enable participants to use their tongue and palate similar to a finger navigating smoothly on a touchpad. The relative position of the tongue on the palate can be used to control the relative position of an icon in a video game (e.g., a character or mouse cursor). If this is applied to the current HM, participants will be able to directly control the angular wrist position rather than the direction of the wrist movement (up-extension or down-flexion), allowing more intuitive control of the TDS-HM.

\section{CONCLUSIONS}

Cumulative research findings and systematic reviews support the efficacy of UL RT for improving motor and functional outcomes in people with stroke. The RT systems that are currently used, however, require the person with stroke to have a minimum degree of UL movement to operate the robot. In our approach, the flexibility and dexterity of the tongue and ease of access to its voluntary motion, made possible via the TDS technology, are exploited to overcome the need for voluntary movement in order to use existing rehabilitation robots (e.g., HM). This case series quantitatively evaluated the extent to which TDS-HM training improved function and QOL in terms of performance of activities of daily living as assessed by the WMFT, FMA, and SIS tests. Two participants with stroke with chronic, moderate UL impairment showed modest decreases in impairment, with functional improvement and improved QOL after a 15-session training program. However, to objectively assess the value of the TDS-HM rehabilitation paradigm in assisting patients with severe UL impairment (with less than $10^{\circ}$ active extension of wrist and fingers), a larger clinical trial is needed to compare changes in level of impairment and health-related QOL following TDS-HM therapy with a therapist-supervised, dose-equivalent usual and customary care control group. In future studies, user satisfaction, engagement, and motivation should also be assessed, and neuroimaging should be used to assess the neurobiology of behavioral change. 


\section{ACKNOWLEDGMENTS}

\section{Author Contributions:}

Study concept and design: M. Ghovanloo, A. J. Butler. Software/hardware implementation: S. Ostadabbas, N. Sebkhi, Z. Zhang.

Acquisition of data: S. N. Housley, K. Richards, D. Wu, M. G. Rodriguez, L. Warthen, C. Yarbrough.

Analysis and interpretation of data: S. Ostadabbas, S. N. Housley, N. Sebkhi.

Drafting of the manuscript: S. Ostadabbas, S. N. Housley, N. Sebkhi. Statistical analysis: S. Ostadabbas, S. N. Housley.

Critical revision of manuscript for important intellectual content:

A. J. Butler, M. Ghovanloo.

Obtained funding: M. Ghovanloo, A. J. Butler.

Administrative, technical, or material support: M. Ghovanloo,

A. J. Butler, S. Balagaje, K. Richards, D. Wu.

Study supervision: M. Ghovanloo, A. J. Butler.

Financial Disclosures: The authors have declared that no competing interests exist.

Funding/Support: This material was based on work supported by the National Center for Advancing Translational Sciences of the National Institutes of Health (NIH) under award number UL1TR000454.

Additional Contributions: The authors would like to thank Motus Nova for donating several Hand Mentor robots for this study and providing technical support. We would also like to thank Carson Scott and Kathleen Grundy from the Department of Physical Therapy at Georgia State University, who actively participated in data collection and provided valuable feedback on different parts of the TDS-HM system. We would also like to thank all participants in this study for their time and valuable feedback.

Institutional Review: All participants provided informed consent to the procedures approved by the institutional review boards of record at Georgia State University and Georgia Tech.

Participant Follow-Up: The authors have no specific plan to notify the study participants of the publication of this article. However, if they are contacted by any participant in the future, the authors will provide them with a copy if interested.

Disclaimer: The content is solely the responsibility of the authors and does not necessarily represent the official view of the NIH.

\section{REFERENCES}

1. Go AS, Mozaffarian D, Roger VL, Benjamin EJ, Berry JD, Borden WB, Bravata DM, Dai S, Ford ES, Fox CS, Franco S, Fullerton HJ, Gillespie C, Hailpern SM, Heit JA, Howard VJ, Huffman MD, Kissela BM, Kittner SJ, Lackland DT, Lichtman JH, Lisabeth LD, Magid D, Marcus GM, Marelli A, Matchar DB, McGuire DK, Mohler ER, Moy CS, Mussolino ME, Nichol G, Paynter NP, Schreiner PJ, Sorlie PD, Stein J, Turan TN, Virani SS, Wong ND, Woo D, Turner MB; American Heart Association Statistics Committee and Stroke Statistics Subcommittee. Heart disease and stroke statistics—2013 update: A report from the
American Heart Association. Circulation. 2013;127(1):e6245. [PMID:23239837]

2. Hesse S, Werner C, Pohl M, Rueckriem S, Mehrholz J, Lingnau ML. Computerized arm training improves the motor control of the severely affected arm after stroke: A single-blinded randomized trial in two centers. Stroke. 2005;36(9):1960-66. [PMID:16109908] http://dx.doi.org/10.1161/01.STR.0000177865.37334.ce

3. Takahashi CD, Der-Yeghiaian L, Le V, Motiwala RR, Cramer SC. Robot-based hand motor therapy after stroke. Brain. 2008;131(Pt 2):425-37. [PMID:18156154] http://dx.doi.org/10.1093/brain/awm311

4. Lo AC, Guarino PD, Richards LG, Haselkorn JK, Wittenberg GF, Federman DG, Ringer RJ, Wagner TH, Krebs HI, Volpe BT, Bever CT Jr, Bravata DM, Duncan PW, Corn BH, Maffucci AD, Nadeau SE, Conroy SS, Powell JM, Huang GD, Peduzzi P. Robot-assisted therapy for longterm upper-limb impairment after stroke. N Engl J Med. 2010;362(19):1772-83. [PMID:20400552] http://dx.doi.org/10.1056/NEJMoa0911341

5. Lum PS, Burgar CG, Shor PC, Majmundar M, Van der Loos M. Robot-assisted movement training compared with conventional therapy techniques for the rehabilitation of upper-limb motor function after stroke. Arch Phys Med Rehabil. 2002;83(7):952-59. [PMID:12098155] http://dx.doi.org/10.1053/apmr.2001.33101

6. Volpe BT, Krebs HI, Hogan N, Edelsteinn L, Diels CM, Aisen ML. Robot training enhanced motor outcome in patients with stroke maintained over 3 years. Neurology. 1999;53(8):1874-76. [PMID:10563646] http://dx.doi.org/10.1212/WNL.53.8.1874

7. Harwin WS, Edgerton VR. Challenges and opportunities for robot-mediated neurorehabilitation. Proc IEEE. 2006; 94:1717-26. http://dx.doi.org/10.1109/JPROC.2006.880671

8. Waldner A, Tomelleri C, Hesse S. Transfer of scientific concepts to clinical practice: Recent robot-assisted training studies. Funct Neurol. 2009;24(4):173-77. [PMID:20412721]

9. Barreca S, Wolf SL, Fasoli S, Bohannon R. Treatment interventions for the paretic upper limb of stroke survivors: A critical review. Neurorehabil Neural Repair. 2003;17(4): 220-26. [PMID:14677218] http://dx.doi.org/10.1177/0888439003259415

10. Kandel ER, Schwartz JH, Jessell TM. Principles of neural science. 4th ed. New York (NY): McGraw-Hill; 2000.

11. Kent RD. The uniqueness of speech among motor systems. Clin Linguist Phon. 2004;18(6-8):495-505.

[PMID:15573486] http://dx.doi.org/10.1080/02699200410001703600

12. Umapathi T, Venketasubramanian N, Leck KJ, Tan CB, Lee WL, Tjia H. Tongue deviation in acute ischaemic 
stroke: A study of supranuclear twelfth cranial nerve palsy in 300 stroke patients. Cerebrovasc Dis. 2000;10(6):46265. [PMID:11070377] http://dx.doi.org/10.1159/000016108

13. Wei CC, Huang SW, Hsu SL, Chen HC, Chen JS, Liang H. Analysis of using the tongue deviation angle as a warning sign of a stroke. Biomed Eng Online. 2012;11:53. [PMID:22908956] http://dx.doi.org/10.1186/1475-925X-11-53

14. Rizzolatti G, Luppino G. The cortical motor system. Neuron. 2001;31(6):889-901. [PMID:11580891] http://dx.doi.org/10.1016/S0896-6273(01)00423-8

15. Stippich C, Blatow M, Durst A, Dreyhaupt J, Sartor K. Global activation of primary motor cortex during voluntary movements in man. Neuroimage. 2007;34(3):1227-37. [PMID:17137794] http://dx.doi.org/10.1016/j.neuroimage.2006.08.046

16. Salmelin R, Sams M. Motor cortex involvement during verbal versus non-verbal lip and tongue movements. Hum Brain Mapp. 2002;16(2):81-91. [PMID:11954058] http://dx.doi.org/10.1002/hbm.10031

17. Huo X, Johnson-Long AN, Ghovanloo M, Shinohara M. Motor performance of tongue with a computer-integrated system under different levels of background physical exertion. Ergonomics. 2013;56(11):1733-44.

[PMID:24003900]

http://dx.doi.org/10.1080/00140139.2013.830779

18. Johnson AN, Huo X, Ghovanloo M, Shinohara M. Dualtask motor performance with a tongue-operated assistive technology compared with hand operations. J Neuroeng Rehabil. 2012;9:1. [PMID:22244362] http://dx.doi.org/10.1186/1743-0003-9-1

19. Lotze M, Flor H, Grodd W, Larbig W, Birbaumer N. Phantom movements and pain. An fMRI study in upper limb amputees. Brain. 2001;124(Pt 11):2268-77. [PMID:11673327] http://dx.doi.org/10.1093/brain/124.11.2268

20. Funk M, Lutz K, Hotz-Boendermaker S, Roos M, Summers P, Brugger P, Hepp-Reymond MC, Kollias SS. Sensorimotor tongue representation in individuals with unilateral upper limb amelia. Neuroimage. 2008;43(1):121-27. [PMID:18617009] http://dx.doi.org/10.1016/j.neuroimage.2008.06.011

21. Boudreau S, Romaniello A, Wang K, Svensson P, Sessle BJ, Arendt-Nielsen L. The effects of intra-oral pain on motor cortex neuroplasticity associated with short-term novel tongue-protrusion training in humans. Pain. 2007; 132(1-2):169-78. [PMID:17870237] http://dx.doi.org/10.1016/j.pain.2007.07.019

22. Motus Nova. Hand Mentor [Internet]. Atlanta (GA): Motus Nova Inc; 2016. Available from: http://motusnova.com/ products/hand-mentor-pro
23. Boyd LA, Vidoni ED, Wessel BD. Motor learning after stroke: Is skill acquisition a prerequisite for contralesional neuroplastic change? Neurosci Lett. 2010;482(1):21-25. [PMID:20609381]

http://dx.doi.org/10.1016/j.neulet.2010.06.082

24. Huo X, Wang J, Ghovanloo M. Introduction and preliminary evaluation of the Tongue Drive System: Wireless tongue-operated assistive technology for people with little or no upper-limb function. J Rehabil Res Dev. 2008; 45(6):921-30. [PMID:19009478] http://dx.doi.org/10.1682/JRRD.2007.06.0096

25. Huo X, Ghovanloo M. Evaluation of a wireless wearable tongue computer interface by individuals with high-level spinal cord injuries. J Neural Eng. 2010;7(2):26008.

[PMID:20332552]

26. Kim J, Huo X, Minocha J, Holbrook J, Laumann A, Ghovanloo M. Evaluation of a smartphone platform as a wireless interface between tongue drive system and electricpowered wheelchairs. IEEE Trans Biomed Eng. 2012; 59(6):1787-96. [PMID:22531737] http://dx.doi.org/10.1109/TBME.2012.2194713

27. Yousefi B, Kim J, Veledar E, Ghovanloo M. Quantitative and comparative assessment of learning in a tongue-operated computer input device-Part ii: Navigation tasks. IEEE Trans Inf Technol Biomed. 2012;16(4):633-43. [PMID:22692932] http://dx.doi.org/10.1109/TITB.2012.2191793

28. Kim J, Bulach C, Richards KM, Wu D, Butler A, Ghovanloo M. An apparatus for improving upper limb function by engaging synchronous tongue motion. Proceedings of the 6th International IEEE/EMBS Conference on Neural Engineering; 2013 Nov 6-8; San Diego, CA. New York (NY): IEEE; p. 1574-77.

29. Lontis E, Lund M, Christensen H, Bentsen B, Gaihede M, Caltenco H, Struijk LA. Clinical evaluation of wireless inductive tongue computer interface for control of computers and assistive devices. Proceedings of the 2010 Annual International Conference of the IEEE Engineering in Medicine and Biology Society; 2010 Aug 31-Sep 4; Buenos Aires, Argentina. New York (NY): IEEE; p. 3365-68.

30. Lontis E, Lotte NS, Struijk A. Alternative design of inductive pointing device for oral interface for computers and wheelchairs. Proceedings of the 2012 Annual International Conference of the IEEE Engineering in Medicine and Biology Society; 2012 Aug 28-Sep 1; San Diego, CA. New York (NY): IEEE; p. 3328-31.

31. Nudo RJ. Functional and structural plasticity in motor cortex: Implications for stroke recovery. Phys Med Rehabil Clin N Am. 2003;14(1 Suppl):S57-76. [PMID:12625638] http://dx.doi.org/10.1016/S1047-9651(02)00054-2 
32. Kleim JA, Barbay S, Nudo RJ. Functional reorganization of the rat motor cortex following motor skill learning. J Neurophysiol. 1998;80(6):3321-25. [PMID:9862925]

33. Biernaskie J, Corbett D. Enriched rehabilitative training promotes improved forelimb motor function and enhanced dendritic growth after focal ischemic injury. J Neurosci. 2001;21(14):5272-80. [PMID:11438602]

34. Nudo RJ, Milliken GW, Jenkins WM, Merzenich MM. Use-dependent alterations of movement representations in primary motor cortex of adult squirrel monkeys. J Neurosci. 1996;16(2):785-807. [PMID:8551360]

35. Ostadabbas S, Butler AJ, Ghovanloo M. Developing a tongue controlled exoskeleton for a wrist tracking exercise: a preliminary study. J Med Devices. 2015;9(3):030912.

36. Wolf SL, Winstein CJ, Miller JP, Taub E, Uswatte G, Morris D, Giuliani C, Light KE, Nichols-Larsen D; EXCITE Investigators. Effect of constraint-induced movement therapy on upper extremity function 3 to 9 months after stroke: The EXCITE randomized clinical trial. JAMA. 2006; 296(17):2095-2104. [PMID:17077374] http://dx.doi.org/10.1001/jama.296.17.2095

37. Kutner NG, Zhang R, Butler AJ, Wolf SL, Alberts JL. Quality-of-life change associated with robotic-assisted therapy to improve hand motor function in patients with subacute stroke: A randomized clinical trial. Phys Ther. 2010;90(4):493-504. [PMID:20185616] http://dx.doi.org/10.2522/ptj.20090160

38. Norkin CC, White DJ. Measurement of joint motion: A guide to goniometry. 4th ed. Philadelphia (PA): F. A. Davis; 2009.

39. Wolf SL, Catlin PA, Ellis M, Archer AL, Morgan B, Piacentino A. Assessing Wolf motor function test as outcome measure for research in patients after stroke. Stroke. 2001;32(7):1635-39. [PMID:11441212] http://dx.doi.org/10.1161/01.STR.32.7.1635

40. Sanford J, Moreland J, Swanson LR, Stratford PW, Gowland C. Reliability of the Fugl-Meyer assessment for testing motor performance in patients following stroke. Phys Ther. 1993;73(7):447-54. [PMID:8316578]

41. Duncan PW, Bode RK, Min Lai S, Perera S; Glycine Antagonist in Neuroprotection Americans Investigators. Rasch analysis of a new stroke-specific outcome scale: The Stroke Impact Scale. Arch Phys Med Rehabil. 2003; 84(7):950-63. [PMID:12881816]

http://dx.doi.org/10.1016/S0003-9993(03)00035-2

42. Lang CE, Edwards DF, Birkenmeier RL, Dromerick AW. Estimating minimal clinically important differences of upper-extremity measures early after stroke. Arch Phys Med Rehabil. 2008;89(9):1693-1700. [PMID:18760153] http://dx.doi.org/10.1016/j.apmr.2008.02.022

43. Shelton FD, Volpe BT, Reding M. Motor impairment as a predictor of functional recovery and guide to rehabilitation treatment after stroke. Neurorehabil Neural Repair. 2001; 15(3):229-37. [PMID:11944745]

http://dx.doi.org/10.1177/154596830101500311

44. Lin KC, Fu T, Wu CY, Wang YH, Liu JS, Hsieh CJ, Lin SF. Minimal detectable change and clinically important difference of the Stroke Impact Scale in stroke patients. Neurorehabil Neural Repair. 2010;24(5):486-92.

[PMID:20053950]

http://dx.doi.org/10.1177/1545968309356295

45. Vellone E, Savini S, Fida R, Dickson VV, Melkus GD, Carod-Artal FJ, Rocco G, Alvaro R. Psychometric evaluation of the stroke impact scale 3.0. J Cardiovasc Nurs. 2015;30(3):229-41. [PMID:24695074] http://dx.doi.org/10.1097/JCN.0000000000000145

46. Wolf SL, Sahu K, Bay RC, Buchanan S, Reiss A, Linder S, Rosenfeldt A, Alberts J. The HAAPI (Home Arm Assistance Progression Initiative) Trial: A novel robotics delivery approach in stroke rehabilitation. Neurorehabil Neural Repair. 2015;29(10):958-68. [PMID:25782693] http://dx.doi.org/10.1177/1545968315575612

47. Norouzi-Gheidari N, Archambault PS, Fung J. Effects of robot-assisted therapy on stroke rehabilitation in upper limbs: Systematic review and meta-analysis of the literature. J Rehabil Res Dev. 2012;49(4):479-96.

[PMID:22773253]

http://dx.doi.org/10.1682/JRRD.2010.10.0210

48. Sale P, Lombardi V, Franceschini M. Hand robotics rehabilitation: Feasibility and preliminary results of a robotic treatment in patients with hemiparesis. Stroke Res Treat. 2012;2012:820931. [PMID:23320252]

49. Frisoli A, Procopio C, Chisari C, Creatini I, Bonfiglio L, Bergamasco M, Rossi B, Carboncini MC. Positive effects of robotic exoskeleton training of upper limb reaching movements after stroke. J Neuroeng Rehabil. 2012;9:36. [PMID:22681653] http://dx.doi.org/10.1186/1743-0003-9-36

50. Wigström H, Gustafsson B. Postsynaptic control of hippocampal long-term potentiation. J Physiol (Paris). 1986; 81(4):228-36. [PMID:2883309]

51. Font MA, Arboix A, Krupinski J. Angiogenesis, neurogenesis and neuroplasticity in ischemic stroke. Curr Cardiol Rev. 2010;6(3):238-44. [PMID:21804783] http://dx.doi.org/10.2174/157340310791658802

52. Geinisman Y, Detoledo-Morrell L, Morrell F, Persina IS, Beatty MA. Synapse restructuring associated with the maintenance phase of hippocampal long-term potentiation. J Comp Neurol. 1996;368(3):413-23. [PMID:8725348] http://dx.doi.org/10.1002/(SICI)10969861(19960506)368:3<413::AID-CNE7>3.0.CO;2-8

53. Atwood HL, Wojtowicz JM. Silent synapses in neural plasticity: Current evidence. Learn Mem. 1999;6(6):542-71. 
[PMID:10641762]

http://dx.doi.org/10.1101/lm.6.6.542

54. Ward NS, Newton JM, Swayne OB, Lee L, Thompson AJ, Greenwood RJ, Rothwell JC, Frackowiak RS. Motor system activation after subcortical stroke depends on corticospinal system integrity. Brain. 2006;129(Pt 3):809-819. [PMID:16421171] https://doi.org/10.1093/brain/awl002

55. Geinisman Y, deToledo-Morrell L, Morrell F. Induction of long-term potentiation is associated with an increase in the number of axospinous synapses with segmented postsynaptic densities. Brain Res. 1991;566(1-2):77-88.

[PMID:1814558] http://dx.doi.org/10.1016/0006-8993(91)91683-R

56. Tillery SI, Taylor DM. Signal acquisition and analysis for cortical control of neuroprosthetics. Curr Opin Neurobiol. 2004;14(6):758-62. [PMID:15582380] http://dx.doi.org/10.1016/j.conb.2004.10.013
Submitted for publication June 29, 2015. Accepted in revised form January 25, 2016.

This article and any supplementary material should be cited as follows:

Ostadabbas S, Housley SN, Sebkhi N, Richards K, Wu D, Zhang Z, Garcia Rodriguez M, Warthen L, Yarbrough C, Balagaje S, Butler AJ, Ghovanloo M. Tongue-controlled robotic rehabilitation: A feasibility study in people with stroke. J Rehabil Res Dev. 2016;53(6):989-1006. http://dx.doi.org/10.1682/JRRD.2015.06.0122

ORCID: Stephen N. Housley, PT: 0000-0002-7046-9109; Andrew J. Butler, PhD, PT: 0000-0003-3869-9120

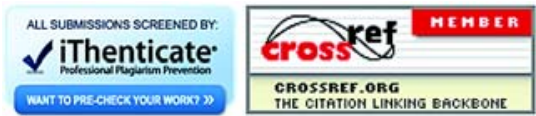


